\section{Patients' attitudes towards trainee surgeons performing cataract surgery at a teaching hospital}

JJ Moodie', I Masood², N Tint'1', M Rubinstein' and SA Vernon ${ }^{1}$

\begin{abstract}
Aim To evaluate patients' preferences of surgeon to perform their cataract surgery if given a choice between consultant and trainee. Methods A questionnaire based patient satisfaction survey was conducted in a large University Teaching Hospital in the UK. One hundred and eighty patients undergoing first eye cataract surgery between January and March 2006 were asked a number of set questions on their preferences regarding the surgeon performing the operation. Primary outcome measure was the patient's preference for who would perform their cataract surgery (consultant or trainee).
\end{abstract}

Results Overall, $126(70 \%)$ accepted that trainee surgeons should operate as part of their training. Only $102(81 \%)$ of these $(57 \%$ of the total) would be happy to be operated on themselves by a supervised surgical trainee. Ninety-eight (78\%) patients objected to being operated on by a trainee if they were to be unsupervised. One hundred and forty-two (79\%) patients stated they would choose to wait longer for their surgery if it meant that a consultant would perform their operation. This preference was held significantly more strongly among patients who had been listed for surgery from a consultant's clinic rather than from the pooled 'cataract clinic' $(P=0.048)$. One hundred and forty-four $(80 \%)$ patients thought they should be told the name and designation of the surgeon who was to perform their operation.

Conclusions Patients undergoing their first cataract procedure appear to have a preference for their named consultant to perform their surgery. If 'patient choice' extends to the choice of operating surgeon, then there are clear implications for the training of future UK ophthalmologists.

Eye (2008) 22, 1183-1186; doi:10.1038/sj.eye.6702872; published online 25 May 2007

Keywords: training; patients; attitudes; surgery; cataract

\section{Introduction}

Each year in the NHS (National Health Service) approximately 270000 people undergo cataract surgery. ${ }^{1}$ The NHS is an all encompassing health care system that has provided health care free at the point of need to UK citizens for over 50 years.

The majority of cataract operations performed in the UK are carried out in NHS hospitals. Many of these operations are performed by ophthalmologists in training. In the UK's current training system, trainee ophthalmologists usually spend 2 or more years at senior house officer (SHO) level followed by $4 \frac{1}{2}$ years as a specialist registrar. During these $6 \frac{1}{2}$ years, trainees are expected to gain a sufficient level of surgical exposure to enable them to perform cataract surgery independently.

Presently, concern has been raised about the state of basic surgical training in the United Kingdom. A recent report suggests that only $42 \%$ of current SHOs in ophthalmology are achieving the Royal College of Ophthalmologists minimum requirement for the number of intraocular procedures within a 2-year period. ${ }^{2}$
${ }^{1}$ Department of Ophthalmology, Queen's Medical Centre, Nottingham, UK

${ }^{2}$ Department of Ophthalmology, Royal Hallamshire Hospital, Sheffield, UK

Correspondence: I Masood Department of

Ophthalmology, A Floor, Royal Hallamshire Hospital, Glossop Road, Sheffield S10 2JF, UK

Tel: +44114271 1900; Fax: + 441142712726

E-mail: imranmasood777@ hotmail.com

Received: 29 December 2006

Accepted in revised form: 27 April 2007

Published online: 25 May 2007

No competing interests 
Within the NHS in general, there is a political drive to give patients more choice in the provision of their care. This applies currently to where the procedure is carried out and may in the future apply to who performs the operation. This study examines one factor that may influence this choice, namely the patients' attitudes to the grade of surgeon undertaking their operation and how this may affect surgical training in the future.

\section{Methods}

A total of 180 anonymous questionnaires were issued to 180 consecutive patients undergoing first eye cataract surgery in a large teaching hospital Eye Department from February to March 2006. All patients willingly participated in the survey, and questionnaires were completed by the patient in the presence of ophthalmic nursing staff. A copy of the questionnaire is shown in Figure $1 .^{3}$ There were two routes by which patients could be listed for cataract surgery. First, patients who were already under the care of a consultant for other eye conditions could be listed from the consultant's clinic. Second, patients could be listed from optometristled cataract clinics in which new referrals without known coexisting ocular pathology were assessed. An equal number of patients from both these routes were recruited to obtain a representative sample of patients undergoing cataract surgery in a teaching hospital setting.

The patients' opinions were collected and then analysed using $\chi^{2}$ frequency tables to assess significant differences in responses according to age (two equalsized groups were formed around the median age of 75 years and compared), sex, the presence of coexisting ocular pathology or not, and the clinic at which they had been listed for surgery (consultant or optometrist led 'cataract clinic').

\section{Results}

All subjects questioned agreed to participate in our study (patient demographics are summarized in Table 1). Overall, 126 out of 180 patients $(70 \%)$ thought that trainee eye surgeons should operate as part of their training. Of these, 102/126 (81\%) felt that they would be happy to be operated on by a trainee if supervised by a consultant (ie $102 / 180,57 \%$ of the total). There was no significant difference in these figures between patient groups according to age, sex, preexisting ocular pathology, and which clinic they were listed from.

Ninety-eight (78\%) patients were unhappy to be operated on by a trainee capable of performing the operation if they were to be unsupervised. This view was held significantly more strongly among female patients

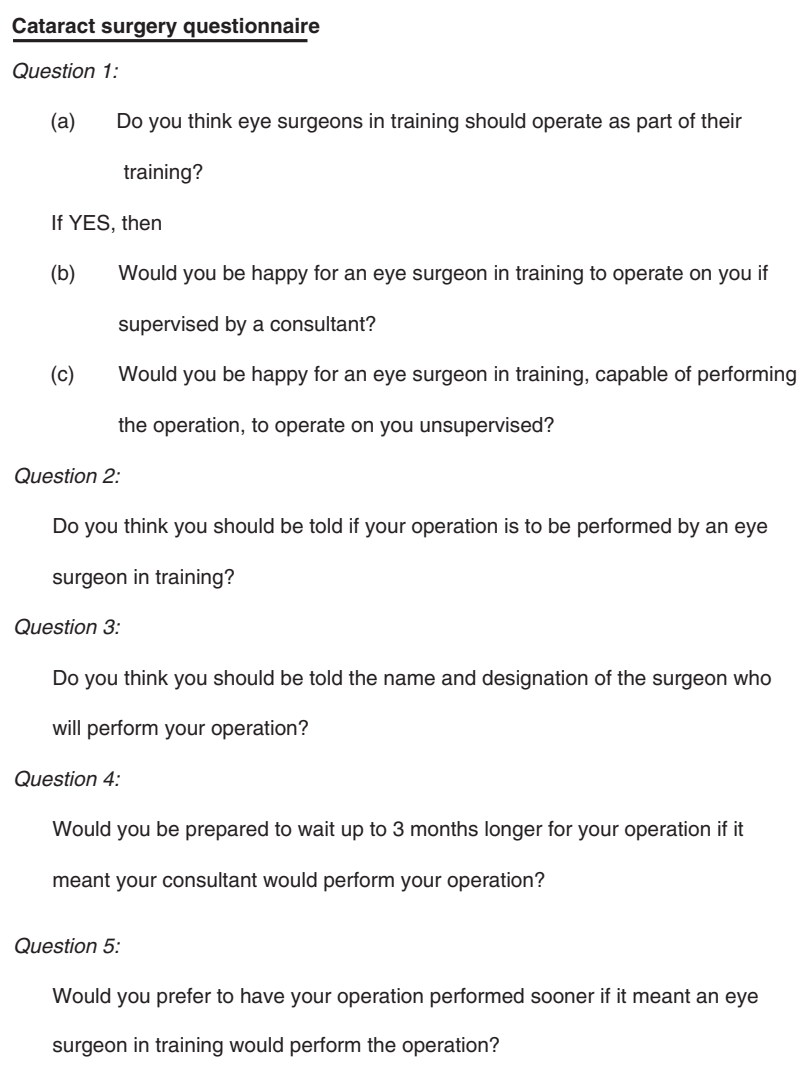

Figure 1 Cataract surgery questionnaire.

(84\% (65 out of 77) $)(P=0.02)$, and those with a coexisting ocular pathology $(87 \%$ (41 out of 47$))(P=0.003)$.

One hundred and forty-four out of $180(80 \%)$ patients wished to know if a trainee was going to perform their operation and the same number felt that they ought to be told the name and designation of their operating surgeon. Again, female patients were significantly more likely to want to know this information (85\% (94/110) vs $71 \%(50 / 70))(P=0.02)$, as well as those with coexisting ocular pathology $(90 \%(64 / 71)$ vs $75 \%$ $(82 / 109))(P=0.01)$

Overall, 142/180 (79\%) patients stated that they would prefer to wait longer for their surgery if it meant that the consultant would perform the operation. However, in a separate question, 55/180 (31\%) said they would be happy for a trainee to perform the operation if it meant that it could be performed sooner (waiting time for cataract surgery was approximately 6 weeks during the time of this study). The number of patients willing to wait 3 months or longer for a guarantee of a consultant operating was significantly greater among those patients listed from a consultant's clinic compared to those from the cataract clinic $(84 \%(88 / 105)$ vs $71 \%(53 / 75)$ $(P=0.048)$. A summary of responses is provided in Table 2 . 


\section{Discussion}

This study highlights some of the attitudes of patients regarding choice of surgeon for first eye elective cataract surgery. These attitudes may influence how doctors manage patients within the evolving NHS.

Approximately $30 \%$ of our patients felt that trainee eye surgeons should not operate as part of their training. This figure is similar to previously published studies. ${ }^{4-6}$ This proportion was not significantly different between the different patient groups. In addition, not all of those that accepted hands on surgical experience is necessary during training would be happy to be operated on themselves by a supervised trainee. These attitudes raise concerns for the viability of the current training of junior ophthalmic surgeons. If some of the patients' wishes were taken to an extreme, it would result in surgical trainees having no 'live' operative experience at all. In cataract surgery, there is no suitable surrogate training model that absolutely simulates the 'live' surgery scenario.

A majority of patients expressed concern for trainees operating unsupervised on patients. A recent survey suggests that $79 \%$ of SHO cataract surgery is supervised by a consultant. ${ }^{6}$ Understandably, there may be concerns among patients regarding complication rates of trainee surgeons compared to consultants. However, several reports show that trainee cataract surgeons have acceptable complication rates providing careful case selection and supervision takes place. ${ }^{7-9}$ Better patient education

Table 1 Patient demographics of study population

\begin{tabular}{ll}
\hline $\begin{array}{l}\text { Study population } \\
\text { Age (years) }\end{array}$ & $n=180$ \\
& $\begin{array}{l}\text { Mean }=74,(\mathrm{SD}=11.1) \\
\text { Median }=75\end{array}$ \\
Rex & $\begin{array}{l}\text { Range }=29-96 \\
\text { Number with coexisting } \\
\text { ocular pathology }(n)\end{array}$ \\
$\begin{array}{c}\text { Number listed from } \\
\text { consultant's clinic }(n)\end{array}$ & $71(39 \%)$ \\
\hline
\end{tabular}

with regard to this may help to alleviate their concern. This highlights the importance of auditing surgical outcomes for both training and consultant surgeons and the results being freely available to patients.

As the quality of health care that patients receive develops, their expectations of how it should be delivered continue to change. A short time ago, in times when waiting lists for cataract surgery were longer, patients tended to attach greater importance to waiting time than the grade of surgeon who would perform their operation. ${ }^{10}$ This feeling is still held strongly in some areas and patients may welcome any initiatives that can reduce the waiting time for their surgery (eg pooled waiting lists, increased usage of independent treatment centres). ${ }^{11}$ Our study suggests that patients have a preference for their named consultant to perform their cataract operation over an ophthalmologist in training. Also, to ensure their named consultant will perform their operation, many would be prepared to wait longer. This preference was held significantly more strongly among those listed from the consultant clinic compared to the 'cataract clinic'.

The continuity of care that the consultant clinic patients had experienced may explain this difference. Patients with coexisting pathologies such as glaucoma or diabetic retinopathy, who have built up a relationship with their consultant over time, are perhaps more likely to have confidence in their consultant than a supervised surgical trainee.

In conclusion, patients are now being empowered to exercise choice in the provision of their medical care within the NHS. The 'choose and book' initiative in primary care is a clear example of this trend. Presently, patients are unable to choose the name or designation of their operating surgeon when listed for a procedure although by choosing certain options, this may always be a 'specialist'. This study suggests, however, that if they were allowed to exercise this choice in the future, there may be serious implications for training in certain surgical procedures.

Table 2 A summary of patients' responses

\begin{tabular}{|c|c|c|c|}
\hline & Yes & No & Don't know \\
\hline Should trainee eye surgeons operate as part of their training? & $126(70 \%)$ & $54(30 \%)$ & 0 \\
\hline $\begin{array}{l}\text { If yes, would you be happy to be operated on by a trainee if } \\
\text { supervised by a consultant? }\end{array}$ & $102(81 \%)$ & $24(19 \%)$ & 0 \\
\hline $\begin{array}{l}\text { If yes, would you be happy to be operated on by a trainee } \\
\text { unsupervised? }\end{array}$ & $28(22 \%)$ & $98(78 \%)$ & 0 \\
\hline $\begin{array}{l}\text { Do you think you should be told if your operation is to be } \\
\text { performed by a trainee eye surgeon? }\end{array}$ & $144(80 \%)$ & $33(28 \%)$ & $3(2 \%)$ \\
\hline $\begin{array}{l}\text { Would you prefer to wait up to } 3 \text { months longer if it meant } \\
\text { your consultant would perform your operation? }\end{array}$ & $142(79 \%)$ & $34(18 \%)$ & $4(3 \%)$ \\
\hline $\begin{array}{l}\text { Would you prefer to have your surgery sooner if it meant a } \\
\text { trainee eye surgeon would perform your surgery? }\end{array}$ & $55(31 \%)$ & $121(66 \%)$ & $4(3 \%)$ \\
\hline
\end{tabular}




\section{References}

1 DoH. Hospital Activity and Episode Statistics. http:// www.doh.gov.uk/public/stats/htm.

2 Watson MP, Boulton MG, Gibson A, Murray PI, Moseley MJ, Fielder AR. The state of basic surgical training in the UK: ophthalmology as a case example. J R Soc Med 2004; 97(4): 174-178.

3 Wiseman OJ, Wijewardenda M, Calleary J, Masood J, Hill JT. Will you be doing my operation doctor? Patient attitudes to informed consent. Ann R Coll Surg Engl 2004; 86: 462-464.

4 Cowles RA, Moyer CA, Sonnad SS, Simeone DM, Knol JA, Eckhauser FE et al. Doctor-patient communication in surgery: attitudes and expectations of general surgery patients about the involvement and education of surgical residents. J Am Coll Surg 2001; 193(1): 73-80.

5 Santen SA, Hemphill RR, McDonald MF, Jo CO. Patients' willingness to allow residents to learn to practice medical procedures. Acad Med 2004; 79(2): 144-147.
6 Vallance JH, Ahmed M, Dhillon B. Cataract surgery and consent; recall, anxiety, and attitude toward trainee surgeons preoperatively and postoperatively. J Cataract Refract Surg 2005; 31(6): 1083.

7 Farrell TA, Deichman CB. Resident cataract surgery. Review of a rural teaching hospital's experience. Ophthalmology 1981; 85(2): 114-116.

8 Tabandeh H, Smeets B, Teimory M, Seward H. Learning phacoemulsification: the surgeon-in-training. Eye 1994; 8(part 4): 475-477.

9 Prasad S. Phacoemulsification learning curve: experience of two junior trainee ophthalmologists. J Cataract Refract Surgery 1998; 24(1): 73-77.

10 Ross MA, Avery AJ, Foss AJ. Views of older people on cataract surgery options: an assessment of preferences by conjoint analysis. Qual Saf Healthcare 2003; 12(1): 13-17.

11 Ramchandani M, Mirza S, Sharma A, Kirkby G. Pooled cataract waiting lists: views of hospital consultants, general practitioners and patients. J R Soc Med 2002; 95(12): 598-600. 